\title{
Práticas Docentes Relacionadas ao Ensino de TRANSFORMAÇÕES GEOMÉTRICAS
}

\author{
Teaching PRactices Related to the Teaching of Geometric \\ TRANSFORMATIONS
}

DOI: http://dx.doi.org/10.23926/RPD.2526-2149.2019.v4.n2.p375-390.id426

\section{João do Espírito Santo Lima Malcher Junior \\ Licenciatura em Matemática (UEPA) \\ professor.malcher@hotmail. com}

\author{
Rosineide de Sousa \\ Jucá \\ Doutora em Educação \\ Ciências e Matemática \\ (UFMT/REAMEC) \\ rosejuca@gmail.com
}

Resumo: Este trabalho tem como objetivo investigar as práticas de
professores de matemática no ensino das Transformações
Geométricas. Como aporte teórico foi feita uma revisão bibliográfica
de estudos referentes ao ensino das Transformações Geométricas,
estudos sobre a formação do professor, e nos documentos oficiais
que norteiam o ensino no Brasil como os Parâmetros Curriculares
Nacionais (1998) e a Base Nacional Comum Curricular (2017). Para
o desenvolvimento da pesquisa elaboramos e aplicamos um
questionário a 20 professores de matemática que atuam na Educação
Básica. Os resultados obtidos apontaram que alguns dos professores
não ensinam as Transformações Geométricas, e os que ensinam
apresentam dificuldade para trabalhar este conteúdo com os alunos,
e que possuem algumas dificuldades metodológicas, além de
possuírem desconhecimento da conexão desse conteúdo com outros
da matemática.

Palavras-chave: Educação Matemática; Transformações Geométricas; Práticas Docentes.

\begin{abstract}
This work aims to investigate the practices of teachers of Basic Education in the teaching of Geometric Transformations. As a theoretical contribution, a bibliographical review of studies related to the teaching of geometric transformations, studies on teacher education, and in the official documents that guide teaching in Brazil as the National Curricular Parameters (1998) and the National Curricular Common Base (2017). For the development of the research, we developed and applied a questionnaire to 20 mathematics teachers who work in Basic Education. The results show that some of the teachers do not teach Geometric Transformations, and those who teach have difficulty working with the students, and that they have some methodological difficulties, as well as being unaware of the connection of this content with others in mathematics.
\end{abstract}

Keywords: Mathematical Education; Geometric Transformations; Teaching Practices. 


\section{INTRODUÇÃO}

As Transformações Geométricas tiveram como um de seus precursores o matemático alemão Félix Klein (1849-1925), que inspirado pelos estudos do conceito de grupo, se dedicou ao desenvolvimento, aplicação e popularização das transformações. Ele também foi um dos líderes do movimento internacional de modernização do ensino de Matemática que ocorreu no final do século XIX e início do século XX em alguns países da Europa, nos Estados Unidos e Rússia, conhecido como Movimento da Matemática Moderna. O objetivo desse movimento foi incorporar no Currículo de Matemática das escolas secundárias da época os novos conhecimentos matemáticos que estavam sendo produzidos, as Transformações Geométricas foram um desses novos conhecimentos.

No entanto, segundo Medeiros (2012), as transformações não detêm a atenção merecida, sendo estudadas superficialmente na Educação Básica, e algumas das vezes não são estudadas nem na Educação Básica e nem no ensino superior. O que se tem observado é um descaso no ensino desse conteúdo nas escolas, seja no ensino fundamental ou no ensino médio, pois alguns professores parecem alheios a este conhecimento.

Os Parâmetros Curriculares Nacionais (PCN), publicados na década de 90, já orientavam para o ensino das Transformações Geométricas, contudo o que se tem visto no contexto escolar é que pouco ou quase nada tem se discutido sobre este tema, dando-se mais enfoque ao ensino de geometria euclidiana. Também a Base Nacional Comum Curricular (BNCC), traz recomendação sobre o ensino gradativo de transformações, que inicia nas séries iniciais, com o estudo das simetrias, e se estende para os anos finais da Educação Básica, sendo proposta não apenas como um conteúdo estanque da Geometria, mas principalmente como uma ferramenta fundamental na aprendizagem e consolidação de outros conhecimentos matemáticos, como a semelhança e congruência de figuras.

Os estudos de Oliveira (2016), Medeiros (2012), Medeiros e Gravina (2015), mostram como o ensino das transformações geométrica vem sendo desenvolvido em sala de aula e as dificuldades dos professores relacionadas a este conteúdo, o que se observa e que tais dificuldades podem estar relacionadas a falta de uma discussão deste conteúdo e de opções metodológicas nos cursos de licenciatura em matemática que permitam ao professor se preparar de forma adequada para ensinar este conteúdo. Pois como coloca Schulman (2005); Imbernón (2011); Tardif (2014), o processo de formação do professor, seja inicial ou continuada deve preparar o mesmo para os desafios da profissão, sejam nos conteúdos específicos a serem ensinados, como no conhecimento pedagógico e curricular desse conteúdo. 
Neste contexto, surgiu o interesse em investigar as práticas de professores de matemática no ensino das Transformações Geométricas, por acreditarmos que tal conteúdo é importante para os alunos da Educação Básica. Para tal elaboramos e aplicamos um questionário a 20 professores que atuam no ensino fundamental e médio de escolas públicas da cidade de Belém do Pará.

\section{A FORMAÇÃo do PROFESSOR de MATEMÁtiCA E O ENSINO dAS TRANSFORMAÇÕES GEOMÉTRICAS}

As discussões sobre a formação de professor apontam que a formação inicial e continuada dos professores deve proporcionar uma série de conhecimentos que os levem a compreender os conteúdos que devem ensinar, bem como conhecer metodologias de ensino que favoreçam a aprendizagem desse conhecimento pelos alunos. Os estudos de Shulman (2005); Darling e Baratz (2005), Imbernón (2011); Tardif (2014), trazem discussões importantes sobre a formação do professor e dos conhecimentos que estes devem possuir para desempenhar bem sua atividade profissional, e os estudos de Blanco (2003), Jaramillo (2003), Nacarato et al (2006), trazem discussões sobre a formação especifica do professor de matemática.

Para Shulman (2005) e Darling e Baratz (2005), a formação dos professores, deve ir além da mera aquisição dos conhecimentos científicos; esses autores defendem que os professores deveriam adquirir nos cursos de formação, seja inicial ou continuada, conhecimentos outros que possam auxiliá-los na sua ação docente. Tais conhecimentos são classificados por Shulman (2005), em: conhecimento do conteúdo, conhecimento curricular e conhecimento pedagógico do conteúdo; esses conhecimentos são necessários para a formação do professor, pois além de fazerem parte da ação docente, somente a valorização do domínio de conteúdo de uma área específica não garante ao professor o desenvolvimento de um trabalho docente eficiente

Na opinião de Imbernón (2011), o processo de formação deve dotar os professores de conhecimentos, habilidades e atitudes para desenvolver profissionais reflexivos ou investigadores. Assim o professor deve ter a capacidade de refletir sobre a própria pratica docente, com objetivo de aprender a interpretar, compreender e refletir sobre a realidade social e à docência. Sobre a formação dos professores Tardif (2014), coloca que os saberes que os professores utilizam para o ensino, não correspondem, ou pelo menos muito pouco, aos conhecimentos teóricos que os professores obtiveram durante a formação inicial e que são produzidos por pesquisas na área de Educação. Assim no entender do autor os conhecimentos 
que os professores adquirem nos cursos de formação parecem estar contribuindo muito pouco para seu trabalho docente.

\begin{abstract}
Os saberes profissionais dos professores parecem ser, portanto, plurais, compósitos, heterogêneos, pois trazem à tona, no próprio exercício da profissão, conhecimentos e manifestações do saber fazer e do saber ser bastante diversificados e provenientes de fontes variadas, as quais podemos supor sejam de naturezas diferentes (TARDIF, 2014, p. 61).
\end{abstract}

Neste sentido, para que o professor tenha competência para desenvolver suas atividades profissionais, alguns saberes precisam ser adquiridos. Os professores precisam se sentir seguros e preparados para enfrentar os desafios da sala de aula, precisam ser competentes para buscarem soluções quando os problemas aparecerem, pois, o contexto escolar apresenta uma diversidade grande de situações que a formação inicial não discute com os professores, se limitando somente a discutir o conhecimento a ser ensinado.

Em relação a formação, seja inicial ou continuada, do professor de matemática entendemos que o professor deve ter conhecimento do conteúdo de matemática, da forma como os alunos aprendem, de propostas diversificadas de metodologias, e ter conhecimento sobre currículo e suas composições. Na colocação de Blanco (2003), o que deve conhecer um professor de matemática está relacionado com os contextos e situações em que ele irá utilizar tal conhecimento, isto é, com atividades, objetivos educacionais e contextos de ensino de matemática. A autora ainda destaca os conhecimentos que devem estar na formação do professor de matemática: conhecimento de e sobre a matemática, conhecimento de e sobre o processo de geração das noções matemáticas; conhecimento de interações em sala de aula e conhecimento sobre a aprendizagem em matemática. Para Jaramillo (2003), pensar a prática do professor de matemática leva a concebê-la como um encontro e uma convergência de diferentes manifestações que se dão num espaço de tempo, onde confluem distintos sujeitos, objetos e fatores: professor, aluno, o currículo e o contexto.

Beatriz D’Ambrósio (1993), aponta quais devem ser as características desejadas de um professor de matemática no século XXI e o que se espera dos cursos de formação. Para ela os professores de Matemática deverão ter visão do que: vem a ser matemática, constitui a atividade Matemática, constitui a aprendizagem e constitui um ambiente propicio à aprendizagem da Matemática. Para a autora dificilmente um professor de matemática formado em um curso de formação que segue um currículo tradicional estará preparado para os desafios das modernas propostas curriculares. 
Feitas essas considerações e destacando o conteúdo das transformações geométricas é que vislumbramos o desenvolvimento dessa pesquisa. Pois a importância das transformações geométricas (isometrias, homotetias), no ensino é algo incontestável, visto que a mesma permite o desenvolvimento de habilidades de percepção espacial e como recurso para induzir de forma experimental a descoberta, por exemplo, das condições para que duas figuras sejam congruentes ou semelhantes (BRASIL, 1998, p. 51). Assim podemos perceber que as transformações são indicadas como um meio para que se alcance a aprendizagem de outros conceitos, atribuindo um caráter instrumental às transformações.

Também a BNCC, Brasil (2017), aponta que o conteúdo de Transformações Geométricas é determinantemente importante para o aspecto funcional que o ensino de geometria deve ter na educação básica, sobretudo as Simetrias. A BNCC indica que nos primeiros anos os alunos devem ser levados a identificar e estabelecer relações com o posicionamento e o deslocamento de objetos espaciais. E que o estudo das simetrias deve ser iniciado por meio da manipulação de representações de figuras geométricas planas em quadriculados ou no plano cartesiano, e com recurso de softwares de geometria dinâmica (BRASIL, 2017). As indicações da BNCC ratificam a importância de se trabalhar este conteúdo de forma dinâmica, que permita aos alunos observarem as relações que serão estabelecidas e chegarem assim as regularidades presentes nas Transformações Geométricas. Além de todas as orientações dadas pelos PCN e BNCC, alguns estudos como de Oliveira (2016), Medeiros (2012), Medeiros e Gravina (2015), dentre outros, mostram como o ensino das transformações geométrica vem sendo desenvolvido em sala de aula.

O estudo de Oliveira (2016), teve por objetivo identificar indícios de (re)construção de conceitos sobre Transformações Geométricas. A pesquisa foi desenvolvida no Espírito Santo, inicialmente, com 22 professores. A autora destaca as dificuldades dos professores participantes em reconhecer possibilidades envolvendo as Simetrias de Reflexão, onde os mesmos não admitiam a sobreposição da imagem refletida sobre o eixo de reflexão.

Outro estudo realizado foi o de Medeiros (2012), que destaca as metodologias no ensino de transformações utilizadas por professores que participaram de sua pesquisa, com objetivo de apresentar uma aplicação das Transformações Geométricas na Educação Básica, bem como responder a perguntas sobre os conhecimentos que os professores consultados detinham sobre o tema. Foram consultados 180 professores que cursavam o programa de pós-graduação lato sensu em Novas Tecnologias no Ensino de Matemática e 11 tutores que atuavam na disciplina tópicos de Geometria no referido programa. 
A autora relata que os professores em sua maioria não estudaram transformações geométricas e perpetuam este desconhecimento quando não ensinam este tema em suas salas de aula. Da análise das respostas dos tutores ao fórum, a autora relata que estes em sua maioria não lembram de haver estudado Transformações Geométricas na educação básica e que no ensino superior estudaram de forma superficial, foi destacado ainda que estes tutores são, no mínimo, especialistas. Ao fim do estudo a autora relata que o objetivo foi alcançado, haja vista que os participantes estiveram abertos a todas as discussões propostas, todavia a autora aponta para a necessidade de uma abordagem mais efetiva sobre as Transformações Geométricas na educação básica e no ensino superior.

Medeiros e Gravina (2015), apresentaram os resultados de uma oficina de formação aplicada a professores do ensino fundamental, realizada em um laboratório de informática de uma escola da rede municipal de Sombrio - SC, com temática voltada ao ensino-aprendizagem das transformações geométricas através do uso do software GeoGebra.

O referido estudo agregou a geometria e a arte através das transformações trabalhadas com os mosaicos de Escher. Após a análise das atividades realizadas as autoras destacaram que a oficina ofertada proporcionou uma experiência didática diferenciada aos participantes, pois permitiu que estes tivessem contato com um software de geometria dinâmica e com um conteúdo pouco trabalhado no ensino fundamental, ressaltando que o uso do software deve ter sempre objetivos bem definidos.

Os estudos supracitados evidenciam que o professor da Educação Básica ainda não tem domínio teórico, prático ou metodológico para ensinar transformações. Uma parcela significativa dos professores participantes nos estudos analisados não domina os conceitos básicos das transformações ou não dominam metodologias de ensino alternativas. Sobre a atuação em sala de aula, Medeiros (2012) apontou que os professores, em sua maioria, não conseguem ensinar as transformações porque não estudaram ou não tiveram qualquer discussão sobre o tema no âmbito da formação inicial ou continuada. Oliveira (2016) relatou outra situação recorrente no trato das transformações pelos professores da educação básica: a falta de alternância de diferentes possibilidades de se ensinar um tema (neste caso, simetrias de reflexão). Em relação as metodologias para o ensino das transformações, Medeiros e Gravina (2015), destacaram a importância de não esvaziar o sentido matemático das metodologias recentemente propostas, como o uso de softwares de geometria dinâmica, fenômeno que pode ser notado quando da falta de discussões sobre o uso de tecnologias, decorrente da falta de discussões sobre transformações geométricas e sobre seu ensino. 


\section{Metodologia de PESQUiSA}

Esta pesquisa é de cunho qualitativa e segue os aspectos da pesquisa descritiva. Que segundo Rudio (2007), o objetivo da pesquisa descritiva é descobrir e observar fenômenos, tentando descrever, classificar e interpretá-los sem interferir nos fatos observados. Assim na pesquisa descritiva é realizado um estudo detalhado, com coleta de dados, análise e interpretação dos mesmos, sem a interação ou envolvimento do pesquisador no assunto analisado.

Neste sentido para a realização desta pesquisa foi elaborado e aplicado um questionário a 20 professores de matemática da cidade de Belém do Pará. Os questionários foram aplicados em uma turma do mestrado profissional de ensino de matemática da Universidade do Estado do Pará, assim como em algumas escolas da cidade de Belém do Pará. E tínhamos o intuito de investigar as práticas desses professores sobre o ensino das Transformações Geométricas.

O questionário elaborado era constituído de duas partes, sendo a primeira relativa a informações pessoais e profissionais dos consultados, como idade, tempo de serviço, etapa de ensino que leciona, rede de ensino em que trabalha, e sobre sua formação acadêmica. A segunda parte é relativa à sua prática pedagógica sobre o ensino das Transformações Geométricas, as questões visam conhecer se o professor ensina este conteúdo, como ensina, que tipo de recursos didáticos utiliza, se os alunos possuem dificuldades em aprender este conteúdo e se o professor possui dificuldade para ensinar. Assim para manter o sigilo sobre a identidade dos professores esses foram identificados por P1, P2, P3,...Pn.

\section{ANÁlISES E DISCUSSÃo DOS RESULTAdOS DA PESQUISA}

A análise da primeira parte do questionário nos permitiu caracterizar os participantes desta pesquisa, como mostra o quadro 1.

Quadro 1 - Caracterização dos sujeitos da pesquisa

\begin{tabular}{|c|c|c|c|c|c|}
\hline $\begin{array}{c}\text { Faixa etária } \\
\text { dos professores }\end{array}$ & $\begin{array}{c}\text { Quantitativo } \\
\text { de } \\
\text { professores }\end{array}$ & $\begin{array}{c}\text { Tempo de } \\
\text { serviço }\end{array}$ & $\begin{array}{c}\text { Quantitativo } \\
\text { de } \\
\text { professores }\end{array}$ & $\begin{array}{c}\text { Formação dos } \\
\text { professores }\end{array}$ & $\begin{array}{c}\text { Quantitativo } \\
\text { de } \\
\text { professores }\end{array}$ \\
\hline 20 a 30 anos & 05 & Menos de 5 anos & 05 & Graduação & 07 \\
\hline 31 a 40 anos & 06 & 5 a 10 anos & 02 & Especialização & 12 \\
\hline $\begin{array}{c}\text { Acima de } 40 \\
\text { anos }\end{array}$ & 09 & 10 a 20 anos & 10 & Mestrado & 01 \\
\hline & $\begin{array}{c}\text { Acima de } 20 \\
\text { anos }\end{array}$ & 03 & & \\
\hline
\end{tabular}

Fonte: Questionário dos professores. 
Quanto a etapa de ensino em que os professores de matemática atuam na Educação Básica, constatamos que seis professores atuam apenas no ensino médio; seis atuam apenas no ensino fundamental; e oito atuam no ensino fundamental e médio. Em relação a rede de ensino que atuam, seis professores atuam somente na rede Estadual, dois atuam somente na rede municipal, dois somente atuam na rede particular, e os demais atuam em mais de uma rede de ensino.

\subsection{AS PRÁtiCAS DOCENTES NO ENSINO DE TRANSFORMAÇÕES GEOMÉTRICAS}

A segunda parte do questionário buscou investigar as práticas dos professores no ensino de Transformações Geométricas. Assim, perguntamos aos professores se os mesmos tiveram disciplinas na graduação ou pós-graduação que discutissem sobre as Transformações Geométricas, constatamos que doze professores tiveram alguma disciplina que enfocasse este conteúdo. Ao especificar qual disciplina oito professores responderam ter discutido o conteúdo em Geometria Analítica, um respondeu em desenho geométrico e geometria euclidiana e quatro responderam Álgebra Linear; no entanto o conteúdo geralmente visto em Geometria Analítica e em Álgebra Linear é "Transformações Lineares" que consiste em uma aplicação algébrica das operações originadas na geometria das transformações.

Assim sendo, percebe-se que os professores não tiveram especificamente um estudo, nem teórico e nem metodológico, sobre as transformações geométricas. Nesse sentido, é necessário que os cursos de formação promovam discussões dos conteúdos de matemática que constituem os currículos escolares para preparar os professores para lidar com os conteúdos que aparecem nesses programas, evitando que os professores deixem de abordar um conteúdo por insegurança ou por não terem estudado na formação inicial. Pois como coloca Imbernóm (2011), ver o docente como um profissional implica que este precisa dominar uma série de capacidades e habilidades especializadas que o fazem ser competente em determinado trabalho.

Perguntamos aos professores se já tinham trabalhado com o conteúdo das transformações geométricas. Observamos que doze professores responderam que não haviam trabalhado as transformações geométricas em sala de aula. Perguntamos aos professores o motivo pelo qual não ensinaram as transformações geométricas. Os professores responderam que:

O conteúdo é muito extenso de geometria. (Professor P5)

Não estava no programa. (Professor P1)

Não apresentou motivo para não ter ensinado. (Professor P11) 
Não atuei nas turmas/séries onde estão situados o tema. (Professor P4)

Julgo o tempo (carga horária) insuficiente, sendo necessário a seleção de conteúdo. (Professor P9)

Necessidade em priorizar conteúdo. (Professor P2)

Falta de tempo. (Professor P10)

Ainda não pois ainda não ministrei aula em turmas que veem esse conteúdo. (Professor P14)

Trabalho a pouco tempo na rede pública, não tive oportunidade de ensinar este conteúdo. (Professor P15)

Falta de planejamento e infraestrutura. (Professor P16)

Pelas respostas dadas notamos que ainda predomina a noção de que os conteúdos são lineares e não articuláveis entre si, bem como, a despeito dos documentos oficiais, o conteúdo não está entre as prioridades dos professores, parece que os professores decidem o que é importante ou não para ser ensinado, quando falam da prioridade de alguns conteúdos. Isso mostra o desconhecimento do professor sobre o currículo e suas articulações e a forma como é pensado e construído. O professor não deve refletir apenas sobre sua prática, mas sua reflexão deve atravessar as paredes da Instituição para analisar todo tipo de interesses subjacentes á educação, á realidade social, com o objetivo concreto de obter a emancipação das pessoas. (IMBERNÓN, 2011, p. 42)

Perguntamos aos professores em quais séries trabalharam as transformações geométricas. Quatro professores responderam que foi no $8^{\circ}$ e $9^{\circ}$ ano, um professor respondeu que no $6^{\circ}$ e $7^{\circ}$ ano, e dois responderam no $2^{\circ}$ e $3^{\circ}$ anos do ensino médio. Quatro responderam que não trabalham e os demais não responderam.

Perguntamos aos professores, quais os conteúdos de transformações geométricas eles trabalharam com seus alunos?

Dos professores que ensinaram as transformações geométricas, cinco professores ensinaram as isometrias, em especial a simetria de reflexão, três ensinaram isometria e homotetia, os demais não responderam.

Perguntamos aos professores, se acham importante o ensino de Transformações Geométricas na Educação Básica e o porquê. Apresentamos as respostas dos professores:

\footnotetext{
Sim, no estudo de função modular. (Professor P1)

Sim, para melhorar a noção e visão de plano e espaço. (Professor P2)

Sim, para dar uma visão espacial e geométrica aos alunos. (Professor P3)

Sim, aumenta o nível de percepção do aluno. (Professor P5)

Sim, pois ajuda o educando a entender diversas formas do cotidiano, perceber padrões e chegar a regularidades. (Professor P6)
} 
Sim, aumenta sua noção geométrica. (Professor P7)

Sim, pois colabora com o desenvolvimento da percepção espacial da turma. (Professor P8)

Sim, pelo fato de permitir a construção do conhecimento geométrico sem apenas a memorização de fórmulas ou resolução de exercícios de maneira mecânica. (Professor P9)

Dá uma ideia mais completa quando trabalhamos com construções e 'desconstruções' de figuras planas, no estudo de área e perímetro. (Professor P12)

Sim, para que os alunos iniciem as noções geométricas. (Professor P14)

Sim, é importante. Os alunos de hoje têm uma pouca noção de espacialidade e formas geométricas. (Professor P16)

Sim, melhora o desenvolvimento de percepção espacial, de representação gráfica. (Professor P17)

Sim. Para que o aluno já nas séries iniciais do fundamental II tenha uma visão espacial das figuras geométricas e o que ocorre quando elas fazem: rotação, reflexão ou translação. (Professor P18)

As respostas dos professores vão de encontro ao que relatou Medeiros (2012) sobre a forma como os professores buscam relacionar as Transformações com outros conteúdos da matemática. A resposta dada pelo professor P5 encontra-se em consonância com o que foi descrito por Medeiros (2012) ao descrever a intrínseca ligação entre as transformações geométricas e as atividades mais elementares da humanidade.

Usar simetrias, rotações, translações e homotetias (ampliações e reduções), copiando o que é apresentado pela natureza, para enfeitar cerâmicas, tecidos e cestas é uma prática humana ancestral (MEDEIROS, 2012, p. 42)

O professor P9 converge com as ideias de Oliveira (2016) quando aponta para a necessidade de construção de um conhecimento que possa ser pluralizado nas experiências em sala de aula. De forma geral, observamos que os professores parecem ter uma compreensão conceitual consistente sobre o tema, pois conseguem enxergar a importância e a relação das transformações geométricas com outros tópicos da matemática. Na opinião de Blanco (2003), é fundamental que os professores tenham conhecimento profundo e compreensão da matemática do currículo escolar e de como ela vincula-se a disciplina matemática.

Perguntamos aos professores como ensinam as Transformações Geométricas. Apenas oito professores responderam, os demais não responderam.

Através de exemplos, com figuras geométricas. (Professor P3)

Faço uso do material didático da escola e complemento com uso do GeoGebra e com aplicação de exercícios. (Professor P6)

Através de planos e desenhos geométricos. (Professor P7)

Utilizando o software GeoGebra. (Professor P8)

Com GeoGebra. (Professor P12) 
Com desenhos, com ajuda de projetores. (Professor P16)

Discutindo situações, sistematizando os conceitos, construindo figuras. (Professor P17)

No plano cartesiano ou com o auxílio do Power Point. (Professor P18)

Observamos pelas respostas dadas que os professores, de maneira geral, conhecem metodologias para o ensino de transformações, mesmo que as mais elementares e, atualmente, preteridas pelas orientações curriculares, como o uso das tecnologias. Assim fica claro que os professores conhecem a importância do uso de tecnologias educacionais disponíveis para a efetivação da aprendizagem de conteúdos matemáticos, como apontado por Medeiros e Gravina (2015).

Imbernón (2011), coloca que um fator importante na capacitação profissional é a atitude do professor ao planejar sua tarefa docente, não apenas como um técnico infalível e sim como um facilitador da aprendizagem, como um prático reflexivo, capaz de provocar a cooperação e a participação dos alunos. E isso vai para além do que o professor aprendeu no curso de formação inicial, pois a auto formação é indispensável para o aperfeiçoamento profissional do professor.

Perguntamos aos professores se conseguem contextualizar os conteúdos de Transformações Geométricas nas suas aulas e de que forma? Os professores responderam que:

Às vezes, com objetos e desenhos do dia a dia. (Professor P1)

Com questões aplicadas no ENEM" (Professor P2)

Sim, pode-se usar por exemplo as obras de arte de Escher para fazer com que os alunos percebam essas regularidades, além de outras formas decorrentes da natureza. (Professor P3)

Questões do cotidiano, incluindo questões do ENEM. (Professor P4)

Nem sempre. (Professor P5)

Usando um espelho consigo mostrar várias propriedades geométricas. (Professor P16)

Construindo figuras, manipulando objetos. (Professor P17)

Sim, mas sempre levando para o desenho técnico, especialmente, nas perspectivas isométricas. (Professor P18)

Observamos que os professores buscam de alguma forma contextualizar esse conteúdo tornando-o compreensível para o aluno. Medeiros (2012) coloca que os professores que buscam contextualizar estes conteúdos o fazem, principalmente, de forma interna as outras áreas da matemática, como a álgebra e a trigonometria. Todavia, alguns conseguem também expandirse a temas transversais, como as formas da natureza e aos objetos do dia a dia do aluno

Talvez uma das dificuldades dos professores na contextualização do conhecimento matemático seja resquício de uma formação inicial deficiente, que prioriza a discussão dos 
conteúdos matemáticos, e tem propiciado poucas discussões metodológicas para os professores. Além do que, o professor precisa aprender a assumir o papel de pesquisador da sua prática pedagógica e deixar de ser um mero seguidor de livros didáticos e de materiais prontos no qual ele não teve participação na elaboração.

Para Tardif (2000), o professor, ao realizar seu trabalho, se apoia nos conhecimentos disciplinares, didáticos e pedagógicos adquiridos na escola de formação; nos conhecimentos curriculares veiculados em programas e livros didáticos, mas considera ainda que eles são provenientes também de sua cultura pessoal, de sua história de vida e de sua escolaridade anterior e no seu próprio saber proveniente de experiências profissionais.

Perguntamos aos professores, se sentiram dificuldades em ensinar os conteúdos de transformações geométricas e quais foram as dificuldades? Apenas cinco professores expuseram suas dificuldades, quatro professores responderam que não tinham dificuldade, os demais não responderam.

Sim, dificuldades em conseguir fazer os alunos perceberem as reflexões, rotações e translações no quadro. (Professor P3)

Sim, a principal dificuldade encontrada foi a falta de atividades produzidas com relação a este tópico. (Professor P6)

Sim, eu senti. A pouca noção de espaço e formas geométricas, e aliado o fato do pouco estudo em casa torna difícil a assimilação. (Professor P16)

Sim, pois a maioria dos alunos não possuem o material pedido. Régua, transferidor, esquadro e compasso. (Professor P17)

Sim. Pois no início tive que estudar para poder visualizar as figuras após as reflexões, rotações e translações. (Professor P18)

As dificuldades apontadas pelos professores encontram-se, principalmente, na dimensão conceitual e metodológica do ensino das transformações, evidenciando a falta de atividades didáticas que proporcione um ensino significativo para o aluno. Além do que, se percebe uma forma de ensino tradicional, ou seja, apenas coma utilização do quadro branco para a representação das figuras, em detrimento das metodologias que utilizam as tecnologias que oferecem mais dinâmica ao ensino e uma maior percepção das transformações pelos alunos. A dificuldade apontada pelo professor P3 aparece no estudo de Medeiros e Gravina (2015) e Medeiros (2012), de modo que ambas sugeriram a utilização do software GeoGebra, haja vista que este permite a observação dos elementos variantes e invariantes das figuras geométricas.

As dificuldades dos professores de ensinar os conteúdos das transformações parecem mostrar a fragilidade na formação, inicial ou continuada, que os mesmos tiveram, e que talvez não tenha provocado situações nas quais os professores fossem levados a refletir sobre a 
importância de saber ensinar, e não apenas de conhecer o conteúdo a ser ensinado. E nos parece que alguns dos professores aprenderam na prática de sala de aula a trabalhar como esse conteúdo, visto que alguns deles colocaram que pouco foi abordado sobre isso no processo de formação.

Nacarato et al (2006), coloca que que o saber profissional do professor se constitui na e a partir da prática pedagógica. É a partir da problematização da prática que o professor passa a refletir e produzir significados para os acontecimentos que vivência. É na dificuldade que os professores encontram na prática de sala de aula que os mesmos adquirem conhecimento, por meio de atitudes investigativas, da reflexão na ação e sobre a ação.

Perguntamos aos professores, se os alunos tiveram dificuldade em compreender os conteúdos de transformações geométricas. Sete professores responderam que os alunos tiveram dificuldade em aprender este conteúdo, três professores responderam que os alunos não tiveram dificuldade, os demais não responderam.

Sim, nas percepções no plano. (Professor P3)

Sim, pois os alunos sentem dificuldades em formar a imagens mentalmente. (Professor P5)

Sim, nas questões que norteiam as propriedades e termos técnicos geométricos. (Professor P8)

A meu ver, o conhecimento que eles tinham era todo baseado em abstrações, nem sempre condizentes com o objeto matemático em estudo. (Professor P12)

Por exemplo em rotação, eles tiveram enorme dificuldade em entender essa simples movimentação. Mesmo usando exemplos práticos. (Professor P16)

Não. (Professor P17)

Algum sim. Exatamente, em poder visualizar o que ocorreria com as figuras, que posições elas iriam ficar com essas transformações geométricas. (Professor P18)

As dificuldades dos alunos podem resultar das dificuldades apresentadas pelos professores de ensinar este conteúdo e das metodologias utilizadas por esses, pois um conteúdo que é apresentado apenas no quadro branco e que indica movimentação dificilmente será visualizado pelos alunos, talvez pela falta de conhecimentos prévios desses ou da sua capacidade de abstração. Assim é importante que o professor compreenda como seus alunos aprendem, considerando suas aptidões e seus conhecimentos prévios, além de aprender a motivar os alunos, o que implica conhecer diversos tipos de tarefas, representações e adaptações dos conteúdos, apoios, tipos de feedback, de forma a mantê-los envolvidos com a atividade proposta. (DARLING e BARATZ, 2005)

De forma geral, as respostas dos professores nos apontaram que o conteúdo de transformações geométricas precisa ser melhor explorado em sala de aula e que os professores 
compreendam a importância desse conteúdo na formação dos alunos da Educação Básica, pois pelas respostas dos professores percebemos que alguns deles não acham esse conteúdo importante. Além do que, a formação desses professores parece não ter possibilitado a eles uma discussão teórica e metodológica sobre o assunto, visto que alguns colocam a dificuldade em ensinar esse conteúdo, e mesmo os professores que utilizam as tecnologias e outros recursos para facilitar a aprendizagem dos alunos, percebe-se ainda uma dificuldade dos alunos em compreender. Assim percebemos que os professores mesmo não tendo recebido uma formação inicial ou continuada referente as transformações geométricas procuram desenvolver seu trabalho buscando diversas alternativas.

Para Jaramillo (2003), ao falar da prática pedagógica significativa em matemática como encontro e convergência entre professor, aluno, currículo e contexto, todos ligados a experiência, estamos manifestando que todos esses elementos devem ser levados em conta, sem que nenhum deles seja reduzido ao outro. Muito pelo contrário, entre eles existe um processo simbiótico, de constantes imbricações, que faz com que essa prática seja vista como um processo altamente complexo e dialético. Um processo no qual o professor está constantemente (re)produzindo, (re)construindo e (re)significando sabres e conhecimento. (JARAMILLO, 2003, p.91)

\section{CONSIDERAÇÕES FinaIS}

O objetivo deste trabalho era investigar as práticas de professores de matemática no ensino das Transformações Geométricas.

A aplicação do questionário e análise das respostas dos 20 professores de matemática, nos permitiu conhecer um pouco das práticas dos professores relacionadas ao ensino das transformações geométricas, observamos que tais práticas são restritas, resultando no ensino deficitário ou na supressão do conteúdo em sala de aula.

Em consonância com estudos supracitados podemos verificar que a formação do professor, seja a formação inicial ou continuada, não está fornecendo subsídios necessários para que o professor possa desenvolver sua prática profissional, visto que os professores ao serem consultados em quais disciplinas estudaram o assunto na formação inicial apresentaram respostas equivocadas.

Com o advento da BNCC, que traz as Transformações Geométricas como elo entre vários conteúdos, e que orienta o trabalho desse conteúdo desde os anos iniciais e sua devida progressão para o ensino fundamental anos finais e o ensino médio, os professores precisam 
refletir de que forma o processo de ensino e aprendizagem deverá ser desenvolvido e quais as metodologias propiciarão a aprendizagem dos alunos de forma significativa. Pois as dificuldades apresentadas, tanto por professores, quanto por seus alunos, evidenciam que os conceitos inerentes e circunscritos das Transformações não estão claros para eles, dificultando que se estabeleçam relações e se alcancem os objetivos, antes propostos pelos PCN e agora propostos pela BNCC.

Neste sentido, acreditamos que os cursos de formação de professores, seja inicial ou continuada, devem promover discussões relacionadas aos conteúdos de Transformações Geométricas, assim como de propostas metodológicas que auxiliem os professores nas suas práticas docentes. Por fim, destacamos a necessidade de aprofundar e de desenvolver pesquisas sobre as transformações geométricas de forma a contribuir com a formação inicial e continuada dos professores dos professores que ensinam matemática.

\section{REFERÊNCIAS}

BLANCO, Maria Mercedes García. A formação inicial de professores de matemática: fundamentos para a definição de um curriculum. In: Formação de professores de matemática: explorando novos caminhos com outros olhares. Campinas, SP: Mercado das letras, 2003.

BRASIL. Ministério da Educação. Base Nacional Comum Curricular: Educação é a base. Terceira versão final. Brasília: MEC, 2018. Disponível em: https://basenacionalcomum.mec.gov.br/a-base.

BRASIL. Parâmetros Curriculares Nacionais: Matemática $-5^{\mathrm{a}}$ a $8^{\mathrm{a}}$ séries. Secretaria de Educação Fundamental. Brasília: MEC/SEF, 1998.

D'AMBROSIO, Beatriz Silva. Formação de professores de matemática para o século XXI: o grande desafio. Revista proposições v. 4 n. 1[10] março, 1993

DARLING-HAMMOND. Linda. BRANSFORD, J. Preparing teachers for a Changing world. What teachers should learn and be able to do. The National Academy of Education. Jossey-BassCA: São Francisco, 2005.

IMBERNÓN, Francisco. Formação docente e profissional: forma-se para a mudança e a incerteza. 9. ed. São Paulo: Cortez, 2011.

JARAMILLO, Diana. Processos metacognitivos na (re) constituição do ideário pedagógico de licenciados em matemática. In: FIORENTINI, D. (ORG). Formação de professores de matemática: explorando novos caminhos e novos olhares. Campinas, SP: Mercado das letras, 2003.

MEDEIROS, Lígia Giesta Ferreira. Dando movimento à forma: as transformações geométricas no plano na formação continuada à distância de professores de matemática. Dissertação (Mestrado em Educação Matemática). Vassouras: Universidade Severino Sombra, 2012.

MEDEIROS, Margarete Farias. GRAVINA, Maria Alice. Geometria dinâmica no ensino de transformações no plano. In: Professor de Matemática Online: Revista eletrônica da Sociedade Brasileira de Matemática. V. 3. N. 1. 2015

NACARATO. Adair Mendes et al. Professores e futuros professores compartilhando aprendizagens: dimensões colaborativas em processo de formação. In: NACARATO, Adair Mendes. PAIVA, Maria 
Auxiliadora Vilela. (Org.). A formação do professor que ensina matemática: perspectivas e pesquisas. Belo Horizonte: Autêntica, 2006.

OLIVEIRA, Sabrine Costa. (Re)construção do pensamento geométrico de professores numa abordagem investigativa sobre simetria de reflexão. In: XII Encontro Nacional de Educação Matemática. São Paulo: Universidade Cruzeiro do Sul, 2016.

RUDIO, Franz Victor. Introdução ao projeto de pesquisa. 34. ed. Petrópolis - RJ: Vozes, 2007.

SHULMAN, Lee. Conocimiento y enseñanza: fundamentos de la nueva reforma. Profesorado. Revista de Currículum y Formación del professorado. v. 9, 2, 2005

TARDIF, Maurice. Saberes Docentes e Formação Profissional. 17 ed. Petrópolis, RJ: Vozes, 2014

TARDIF, Maurice. Saberes profissionais dos professores e conhecimentos universitários: elementos para uma epistemologia da prática profissional dos professores e suas consequências em relação à formação para o magistério, In: Revista Brasileira da Educação, n. ${ }^{\circ}$ 13. ANPED. São Paulo, 2000.

Recebido em: 12 de março de 2019.

Aprovado em: 14 de maio de 2019. 